\title{
Gender-specific cardiovascular outcomes in patients undergoing percutaneous coronary intervention in Chinese populations
}

\author{
Juan Long, Fanfang Zeng, Lili Wang, Chen Yi, Qiying Chen and Honglei Zhao* (D)
}

\begin{abstract}
Background: Data was limited on the rates of in-hospital and 30-days composite outcomes between male and female patients with coronary heart disease (CHD) undergoing percutaneous coronary intervention ( $\mathrm{PCl}$ ).

Methods: This was a retrospective study and CHD patients undergoing PCI between January and December of 2018 were screened and recruited. Baseline characteristics, in-hospital and 30-days composite outcomes were compared by gender. The factors influencing gender-outcome associations were evaluated.

Results: A total of $672 \mathrm{CHD}$ patients undergoing PCI were included into current analysis. Compared to males, females were older ( $53.8 \pm 12.7$ years vs $50.6 \pm 11.8$ years), more likely to be obese (32.9\% vs $29.4 \%)$ and had higher prevalence of hypertension ( $46.7 \%$ vs $41 \%)$. Females were less likely to be smoker (30.3\% vs $1.1 \%$ ), have prior history of CHD (4.4\% vs 10.9\%), and lower socioeconomic status [SES; full-time employment (64.4\% vs $71.9 \%)$, education attainment $\geq$ college (29.6\% vs $36.8 \%$ ) and annual income $\geq 60,000$ RMB (23.7\% vs $27.1 \%)$. Hospitalized stay was longer in females (median 5.2 vs 4.0 days), and females were more likely to experience in-hospital bleeding (3.0\% vs $1.2 \%$ and 30 -days non-fatal myocardial infarction (5.9\% vs $2.9 \%$ ). In unadjusted model, compared to males, females had a crude odds ratio (OR) of 2.05 (95\% confidence interval [CI] 1.68-2.59) for in-hospital composite outcomes and 2.16 (95\% Cl 1.74-2.63) for 30-days post-PCl composite outcomes. After adjustment for potential covariates, female gender remains independently associated with in-hospital and 30-days post-PCl composite outcomes. OR change was the greatest with adjustment for SES when compared to other covariates.
\end{abstract}

Conclusion: Compared to male patients, female patients had a higher risk of in-hospital and 30-days composite outcomes post-PCI treatment, which were mainly attributed to the differences in SES.

Keywords: Coronary heart disease, Gender, Cardiovascular outcomes

\footnotetext{
* Correspondence: zhldoctor@tom.com

Department of Cardiology, Fuwai Hospital Chinese Academy Science of

Medical Science, Shenzhen, China
}

(c) The Author(s). 2020 Open Access This article is licensed under a Creative Commons Attribution 4.0 International License, which permits use, sharing, adaptation, distribution and reproduction in any medium or format, as long as you give appropriate credit to the original author(s) and the source, provide a link to the Creative Commons licence, and indicate if changes were made. The images or other third party material in this article are included in the article's Creative Commons licence, unless indicated otherwise in a credit line to the material. If material is not included in the article's Creative Commons licence and your intended use is not permitted by statutory regulation or exceeds the permitted use, you will need to obtain permission directly from the copyright holder. To view a copy of this licence, visit http://creativecommons.org/licenses/by/4.0/. The Creative Commons Public Domain Dedication waiver (http://creativecommons.org/publicdomain/zero/1.0/) applies to the data made available in this article, unless otherwise stated in a credit line to the data. 


\section{Background}

Coronary heart disease (CHD) is a leading cause of morbidity and mortality in the developed countries [1-3]. In the last decades, however, the prevalence and incidence of CHD in China is increased dramatically, which is largely attributed to the endemic of cardiovascular risk factors including obesity, smoking, hypertension, dyslipidemia, and diabetes mellitus [4-6]. Notably, percutaneous coronary intervention (PCI) is one of the important therapeutic approaches for CHD patients, especially for those with acute coronary syndrome (ACS) [7]. Prior studies have demonstrated that primary PCI therapy improves the outcomes of ACS patients [8-10]. However, most of prior studies recruited patients from developed countries and female patients were always underrepresented [8-10].

China Cardiovascular Disease Report shows that the number of CHD patients undergoing PCI was increased annually in China, and compared to male patients, female patients were less likely to receive primary PCI with an ACS presentation [11-13]. Prior studies from developed countries have shown that female patients undergoing PCI had more procedure-related complications and poorer outcomes than their male counterparts, however, data on the gender-specific outcomes in Chinese CHD patients undergoing PCI were limited. With aging and endemic of cardiovascular risk factors, the prevalence and incidence of CHD among postmenopausal females were approaching to or even surpassing that of male patients $[5,14,15]$. Therefore, elucidating gender-specific outcomes among CHD patients undergoing PCI is clinically important in China.
Herein, we conducted a retrospective study and enrolled CHD patients undergoing PCI in our hospital. The aims of current study were to: 1 ) compare the risks of in-hospital and 30-days composite outcomes post-PCI treatment between male and female patients; 2) evaluate the association of gender and of in-hospital and 30-days composite outcomes post-PCI treatment. We believe that the results from current study would provide clues for further studies to elucidate the mechanisms underlying the gender disparities in outcomes in China, which in turn could help to reduce these disparities.

\section{Methods}

\section{Study participants enrollment}

This was a retrospective study and no written informed consent was required. Our current study was approved by the Clinical and Basic Research Ethic Committee of Fuwai Hospital, Shenzhen, China. From January to December of 2018, CHD patients admitted to our hospital to undergo PCI were screened, and those who did have not successful PCI were excluded. A total of 689 patients undergoing PCI were screened and 17 patients who did not underwent successful PCI were excluded (Fig. 1), and 672 patients were finally included into current analysis and were divided into male and female groups.

\section{Baseline characteristics collection}

Baseline characteristics including demographics (age and sex), risk factors (smoking, obesity, hypertension, dyslipidemia, diabetes mellitus), comorbidities (prior history of ischemic stroke, CHD, peripheral vascular disease

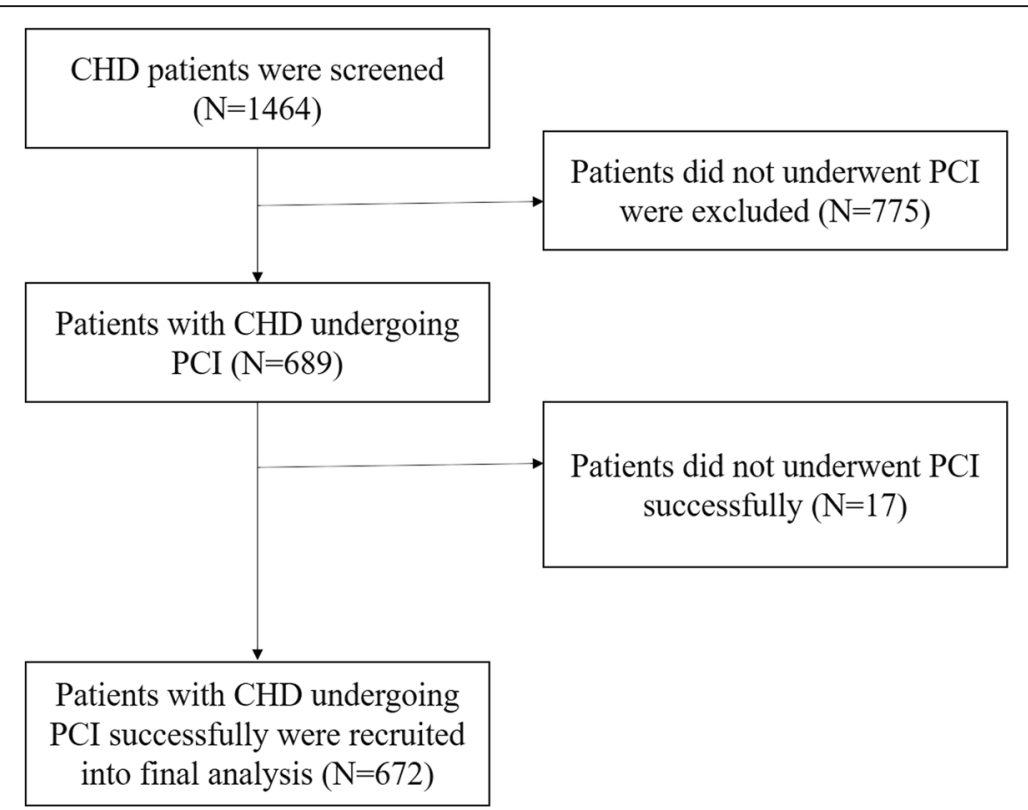

Fig. 1 Study flow chart 
[PVD], chronic kidney disease [CKD], heart failure $[\mathrm{HF}]$ ), laboratory parameters (fasting plasma glucose [FPG], total cholesterol, serum creatinine), and socioeconomic status (SES; employment status, education attainment and annual personal income) were collected from electronic health record of our hospital.

\section{Peri-PCl characteristics}

Peri-PCI characteristics including indications for PCI (ACS or stable angina), urgent or elective PCI, radial or femoral artery access, and number and type of stents implanted were collected from electric health record of our hospital.

\section{Study outcomes}

Study outcomes in our current analysis included inhospital composite outcomes (acute stent thrombosis, bleeding events and all-cause mortality), and 30-days
post-PCI composite outcomes (early stent thrombosis, non-fatal MI, bleeding events and all-cause mortality). Non-fatal MI was diagnosed based on clinical symptoms (e.g. chest pain), electrocardiographic changes (e.g. ST-T segment elevation or depression and $\mathrm{T}$ wave inversion), and presence of myocardial injury. In specific, myocardial injury was defined as plasma concentration of cardiac troponin level above the 99th percentile upper reference limit. Briefly, in our routinely clinical practice, cardiac troponin was measured using point of care first. At the same time, blood sample would be sent to the Core lab of our hospital to measure plasma concentration of cardiac troponin. Diagnosis of myocardial injury was based on plasma concentration of cardiac troponin. The Academic Research Consortium (ARC) definition was used to diagnose stent thrombosis with definite evidence from coronary angiography. Bleeding events were defined based on the Global Utilization of Streptokinase

Table 1 Baseline characteristics comparisons

\begin{tabular}{|c|c|c|}
\hline Variables & Male $(n=402)$ & Female $(n=270)$ \\
\hline Age (years) & $50.6 \pm 11.8$ & $53.8 \pm 12.7^{*}$ \\
\hline \multicolumn{3}{|l|}{ Comorbidities } \\
\hline Obese, n (\%) & $118(29.4)$ & $88(32.9)^{*}$ \\
\hline Current smoker, n (\%) & $122(30.3)$ & $3(1.1)^{*}$ \\
\hline Hypertension, n (\%) & $165(41)$ & $126(46.7)^{*}$ \\
\hline Diabetes mellitus, n (\%) & $80(19.9)$ & $49(18.1)$ \\
\hline Dyslipidemia, n (\%) & $124(30.8)$ & $84(31.1)$ \\
\hline Heart failure, n (\%) & $30(7.7)$ & $18(6.7)$ \\
\hline Coronary heart disease, n (\%) & $44(10.9)$ & $12(4.4)^{*}$ \\
\hline Ischemic stroke, n (\%) & $23(5.7)$ & $14(5.2)$ \\
\hline Chronic kidney disease, n (\%) & $19(4.7)$ & $12(4.4)$ \\
\hline Peripheral vascular disease, n (\%) & $20(5.0)$ & $8(3.0)$ \\
\hline \multicolumn{3}{|l|}{ Socioeconomic status } \\
\hline Full-time employment, n (\%) & $289(71.9)$ & $174(64.4)^{*}$ \\
\hline Education $\geq$ college, n (\%) & $148(36.8)$ & $80(29.6)^{*}$ \\
\hline Annual personal income $\geq 60,000$ RMB, n (\%) & $109(27.1)$ & $64(23.7)^{*}$ \\
\hline \multicolumn{3}{|l|}{ Procedural characteristics } \\
\hline Acute coronary syndrome, n (\%) & $269(66.9)$ & $185(68.5)$ \\
\hline Urgent PCI status, n (\%) & $256(63.7)$ & $174(64.4)$ \\
\hline Femoral artery access, n (\%) & $169(42.0)$ & $118(43.7)$ \\
\hline Lesion length (mm) & $26.5 \pm 11.4$ & $24.1 \pm 10.3^{*}$ \\
\hline Number of stents & $2.1 \pm 0.8$ & $2.0 \pm 0.7$ \\
\hline Drug-eluting stents, n (\%) & $387(96.3)$ & $258(95.6)$ \\
\hline \multicolumn{3}{|l|}{ Laboratory parameters } \\
\hline Fasting plasma glucose (mg/dL) & $92.6 \pm 12.5$ & $91.3 \pm 13.4$ \\
\hline Total cholesterol (mmol/L) & $5.0 \pm 0.9$ & $5.0 \pm 1.0$ \\
\hline Creatinine (umol/L) & $63.5 \pm 21.2$ & $60.6 \pm 19.5$ \\
\hline
\end{tabular}

$P C l$ Percutaneous coronary intervention; ${ }^{*} P<0.05$ versus male patients 
and Tissue Plasminogen Activator for Occluded Arteries (GUSTO) criteria. Medications use during hospitalization and after discharge were recorded.

\section{Statistical analysis}

Continuous variables were presented as mean \pm SD and compared by student $t$ test; categorical variables were presented by number and percentages and compared by the chi-square or Fisher exact test. Logistic regression analysis was performed to evaluate the association between female gender and in-hospital and 30-days post-PCI composite outcomes (male sex was served as reference group), respectively. Statistical analyze were computed using SPSS 17.0 (SPSS Inc., Chicago, IL). All statistical tests were two-sided and considered statistically significant when $P<0.05$.

\section{Results}

\section{Baseline characteristics comparison by gender}

Female patients accounted for $40.2 \%(n=270)$ of current analysis. As presented in Table 1, compared to male patients, female patients were older $(53.8 \pm 12.7$ years vs $50.6 \pm 11.8$ years $)$, more likely to be obese $(32.9 \%$ vs $29.4 \%$ ) and had prevalence of hypertension (46.7\% vs 41\%). Female patients were less likely to be smoker (30.3\% vs $1.1 \%)$, had prior history of $\mathrm{CHD}(4.4 \%$ vs $10.9 \%)$, and had full-time employment (64.4\% vs $71.9 \%)$, education attainment $\geq$ college $(29.6 \%$ vs $36.8 \%)$ and annual income $\geq 60,000$ RMB ( $23.7 \%$ vs $27.1 \%)$. No significant between-group differences in acute coronary syndrome presentation (68.5\% vs $66.9 \%)$, undergoing urgent PCI (63.7\% vs $64.4 \%)$, femoral artery access $(42.0 \%$ vs $43.7 \%)$, number of stents $(2.1 \pm 0.8$ vs $2.0 \pm 0.7)$ and drug-eluting stent implanted (96.3\% vs $95.6 \%)$ were observed, except for the significant difference in length of the lesion $(26.5 \pm 11.4 \mathrm{~mm}$ vs $24.1 \pm 10.3 \mathrm{~mm})$.

\section{Medications used comparison by gender}

Medications used during hospitalization and after discharge were compared. As presented in Table 2, no significant differences in medications used during hospitalization and follow-up by gender were observed except for a lower use of angiotensin converting enzyme inhibitor/angiotensin receptor blocker.

\section{Comparisons of outcomes}

As presented in Table 3, compared to male patients, hospitalized stay was longer in female patients (median days: 5.2 vs 4.0 ), and female patients were more likely to experience in-hospital bleeding (3.0\% vs $1.2 \%)$ and 30 days non-fatal myocardial infarction (5.9\% vs $2.9 \%)$. No significant gender differences in acute- and early-stent thrombosis, 30-days bleeding and all-cause mortality were observed.
Table 2 Medications used comparisons by gender

\begin{tabular}{lll}
\hline Variables & Male $(n=402)$ & Female $(n=270)$ \\
\hline During hospitalization & & \\
Aspirin, n (\%) & $402(100)$ & $270(100)$ \\
Clopidogrel, n (\%) & $368(91.5)$ & $246(91.1)$ \\
Ticagrelor, n (\%) & $32(8.0)$ & $20(7.4)$ \\
Statins, n (\%) & $380(94.5)$ & $252(93.3)$ \\
ACEl/ARB, n (\%) & $342(85.1)$ & $220(81.5)^{*}$ \\
Beta-blocker, n (\%) & $330(82.1)$ & $218(80.7)$ \\
LMWH, n (\%) & $25(6.2)$ & $12(4.4)$ \\
Warfarin, n (\%) & $0(0)$ & $0(0)$ \\
PPI, n (\%) & $219(54.5)$ & $152(56.3)$ \\
During follow-up & & \\
Aspirin, n (\%) & $398(99.0)$ & $265(98.1)$ \\
Clopidogrel, n (\%) & $362(90.0)$ & $242(89.6)$ \\
Ticagrelor, n (\%) & $28(7.0)$ & $16(5.9)$ \\
Statins, n (\%) & $380(94.5)$ & $252(93.3)$ \\
ACEI/ARB, n (\%) & $340(84.6)$ & $215(79.6)^{*}$ \\
Beta-blocker, n (\%) & $330(82.1)$ & $216(80.0)$ \\
LMWH, n (\%) & $0(0)$ & $0(0)$ \\
Warfarin, n (\%) & $3(0.7)$ & $2(0.7)$ \\
PPI, n (\%) & $187(46.5)$ & $132(48.9)$ \\
\hline ACEIARB Ang &
\end{tabular}

ACEI/ARB Angiotensin converting enzyme inhibitor/angiotensin receptor blocker, LMWH Low molecular weight heparin, PPI Proton pump inhibitor; * $P<0.05$ versus male patients

\section{Association of female gender and outcomes}

As presented in Table 4, in unadjusted model, compared to male patients, female patients had a crude odds ratio of 2.05 for in-hospital composite outcomes. After adjusted for age, the odds ratio reduced by $22 \%$; with further adjustment for comorbidities in model 2, the odds ratio reduced by $28 \%$; and after adjustment for SES in model 3 , the odds ratio reduced by $35 \%$, with odds ratio of 1.20 (95\% confidence interval 1.10-1.43).

Female patients also had a crude odds of 2.16 for 30 days composite outcomes. After adjusted for age, the odds ratio reduced by 19\%; with further adjustment for comorbidities, the odds ratio reduced by $37 \%$; and after adjustment for SES, the odds ratio reduced by $40 \%$, with odds ratio of 1.20 (95\% confidence interval 1.12-1.51).

\section{Discussion}

There are two important findings of current study. First, compared to male patients, female patients have higher risk of in-hospital bleeding and 30-days non-fatal MI. Second, after adjustment for potential covariates, female gender remains independently associated with in-hospital and 30-days composite outcomes. Further researches are needed to elucidate the underlying mechanisms and to implement interventions targeting the mechanisms for 
Table $\mathbf{3}$ Comparisons of outcomes

\begin{tabular}{|c|c|c|}
\hline Outcomes & Male $(n=402)$ & Female $(n=270)$ \\
\hline \multicolumn{3}{|l|}{ In-hospital } \\
\hline Median stay in hospital (days) & $4.0(2.9-6.1)$ & $5.2(3.3-6.8)^{*}$ \\
\hline Bleeding events, n (\%) & $5(1.2)$ & $8(3.0)^{*}$ \\
\hline Acute stent thrombosis, n (\%) & $2(0.5)$ & $3(1.1)$ \\
\hline All-cause mortality, n (\%) & $0(0)$ & $0(0)$ \\
\hline \multicolumn{3}{|l|}{ 30-days } \\
\hline Bleeding events, n (\%) & $8(2.0)$ & $5(1.9)$ \\
\hline Early stent thrombosis, n (\%) & $2(0.5)$ & $2(0.7)$ \\
\hline Non-fatal myocardial infarction, n (\%) & $2(0.5)$ & $7(2.6)^{*}$ \\
\hline All-cause mortality & 0 & $1(0.4)$ \\
\hline
\end{tabular}

observed gender differences in clinical outcomes so as to narrow these health disparities by gender.

Numerous studies from the United States and European countires have consistently demonstrated that compared to male patients, female patients undergoing PCI have higher rates of re-hospitalization and all-cause mortality. For example, one systemic review shows that compared to males with ST-segment elevation myocardial infarction (STEMI), females with STEMI had higher mortality rate and this difference was partially attributed to the differences in baseline cardiovascular risk profiles [16]. Otten $\mathrm{AM}$ et al. reported that the gender differences in mortality post primary PCI were age dependent, and although young women had a lower risk before PCI, survival rate was lower in women when compared to similarly aged men [17]. In patients with ACS, Pendyala et al. found that compared to men, women experienced higher 1-year risk of mortality and major adverse cardiovascular events postPCI [18]. One recent study from Chinese population with ACS showed that women received less optimal treatment than men during hospitalization, and the higher in-

Table 4 Associations of female gender and composite outcomes

\begin{tabular}{ccc}
\hline Models & Odds ratio & 95\% Confidence interval \\
\hline $\begin{array}{ccc}\text { In-hospital composite outcomes } \\
\text { Unadjusted }\end{array}$ & 2.05 & $1.68-2.59$ \\
Model 1 & 1.83 & $1.50-2.22$ \\
Model 2 & 1.55 & $1.30-1.92$ \\
Model 3 & 1.20 & $1.10-1.43$ \\
30-days composite outcomes & \\
Unadjusted & 2.16 & $1.74-2.63$ \\
Model 1 & 1.97 & $1.62-2.40$ \\
Model 2 & 1.60 & $1.35-1.94$ \\
Model 3 & 1.20 & $1.12-1.51$ \\
\hline
\end{tabular}

Model 1, adjusted for age; model 2, further adjusted for chronic kidney disease, diabetes mellitus, hypertension, dyslipidemia, and lesion length; model 3, further adjusted for annual income and education attainment hospital mortality rate in women was majorly attributed to the difference in clinical profiles and in-hospital treatment [3]. Consistent with prior studies, our current study also demonstrates that female patients undergoing PCI has a higher risk of in-hospital and 30-days composite outcomes. These differences were mainly driven by the differences in in-hospital bleeding events and 30-days non-fatal myocardial infarction. However, it was worth to note that there were some differences between our current study and the prior study from Chinese populations [3]. First, prior Chinese study enrolled ACS patients while current study enrolled both stable and ACS patients. Second, participants in prior study had higher comorbid burdens than participants in our current study as reflected by the older age, higher prevalence of hypertension, diabetes mellitus, CKD and among others in prior study. Third, prior study only evaluated the in-hospital events while our current study evaluated both in-hospital and 30-days events after PCI treatment. Although somewhat differences, both our current study and prior large national study together suggested that women with CHD undergoing PCI had higher cardiovascular risks and sex-specific managements are needed to narrow these health disparities in China.

The mechanisms attributed to gender differences in outcomes vary between different studies, including differences in biological features, baseline cardiovascular risk profiles, treatment received during hospitalization and after discharge, medication adherence, and among others [19-22]. In current study, we used regression models to evaluate the changes of odds ratio between different models. We observed that the association of female gender and in-hospital and 30-days composite outcomes were attenuated with greatest magnitude after adjustment for SES, suggesting that compared to age and other traditional cardiovascular risk factors, SES played a more important role in gender differences in clinical outcomes. In current analysis, we included education attainment, personal annual income and 
employment status as indicators of SES. Numerous studies have demonstrated that compared to individuals with higher SES, those with lower SES had higher cardiovascular risk post-PCI treatment. To our knowledge, this was the first study to evaluate the influence of SES on gender differences in clinical outcomes post-PCI treatment in Chinese populations. The explanations for SESmediated gender differences in clinical outcomes might be multifactorial such as poor lifestyle and behavior (e.g. smoking and physical inactivity), greater burden of risk factors, and lower medications adherence [23-25]. Future studies are needed to corroborate our findings as well as to elucidate the underlying mechanisms in Chinese populations. Lastly, it is important to note that prior study has shown the urban-rural disparities in treatments and outcomes after ST-elevation myocardial infarction in China [26]. However, current study did not have the ability to evaluate whether the gender differences in clinical outcomes were attributed to the differences between urban and rural resident because all participants were from the urban area of Shenzhen city and the medical costs were universal paid by the health insurance.

There are some limitations of current study. First of all, this was a retrospective study and findings from current analysis should not be drawn a causal relationship. Second, although we had adjusted for potential confounding factors, the undetected and unmeasured factors might still exist that could influence the genderoutcome association. Third, current study was conducted in Chinese populations and whether the findings can be extrapolated to other race/ethnic groups was unknown. Fourth, since we had only followed up patients for 30 days, whether the gender differences in clinical outcomes persist with longer follow-up was also unknown. Fifth, the sample size of the current analysis was relatively small and large prospective studies are needed to corroborate the current findings. Last but not the least, this was a single center retrospective study, and as mentioned above that there were some differences in clinical profiles between current study and prior national prospective cohort study from Chinese populations, future studies are needed to evaluate the reasons for these different findings across studies through collaboration.

\section{Conclusion}

In conclusion, our current study shows that in CHD patients, compared to male patients, female patients have a higher risk of in-hospital and 30-days composite outcomes post-PCI treatment. The differences in clinical outcomes are mainly attributed to the differences in SES.

\section{Abbreviations}

CHD: Coronary heart disease; MI: Myocardial infarction; PCl: Percutaneous coronary intervention; ACS: Acute coronary syndrome; PVD: Peripheral vascular disease; CKD: Chronic kidney disease; HF: Heart failure; FPG: Fasting plasma glucose; SES: Socioeconomic status; Cl: Confidence interval

\section{Acknowledgments}

We appreciate very much for Dr. Fang Yang assisting in conducting statistical analysis and critically review our paper.

\section{Authors' contributions}

$H L Z$ and $J$ conceived the study, participated in the design and drafted the manuscript; FFZ performed the statistical analyses; LLW, CY and QYC collected the data. All authors read and approved the final manuscript.

\section{Funding}

This study was supported by the Shenzhen Technology Grant (JCYJ20180302174003513). The funding bodies played no role in the design of the study and collection, analysis, and interpretation of data and in writing the manuscript.

\section{Availability of data and materials}

The datasets used and/or analysed during the current study available from the corresponding author on reasonable request.

\section{Ethics approval and consent to participate}

The study design was approved by the Clinical and Basic Research Ethic Committee of Fuwai Hospital. This was a retrospective study and no written informed consent was required.

\section{Consent for publication}

Not Applicable.

\section{Competing interests}

None.

Received: 23 August 2019 Accepted: 2 June 2020

Published online: 09 June 2020

\section{References}

1. Jiang J, Hong T, Yu R, Zhang Y, Liu Z, Huo Y. Knowledge of secondary prevention guidelines for coronary heart disease: results from a physicians survey in China. Eur J Prev Cardiol. 2012;19(5):991-8.

2. Wang Y, Ma H, Yang J, Chen Q, Lu L, Zhang R. Lipoprotein(a) is associated with left ventricular systolic dysfunction in a Chinese population of patients with hypertension and without coronary artery disease. Arch Med Sci. 2017; 13(5):1078-85

3. Hao Y, Liu J, Liu J, et al. Sex Differences in In-Hospital Management and Outcomes of Patients With Acute Coronary Syndrome. Circulation. 2019; 139(15):1776-85.

4. Z Zhang XH, Lu ZL, Liu L. Coronary heart disease in China. Heart. 2008;94(9): 1126-31.

5. Jiang G, Wang D, Li W, et al. Coronary heart disease mortality in China: age, gender, and urban-rural gaps during epidemiological transition. Rev Panam Salud Publica. 2012;31(4):317-24.

6. Wang X, Gao M, Zhou S, et al. Trend in young coronary artery disease in China from 2010 to 2014: a retrospective study of young patients $\leq 45$. BMC Cardiovasc Disord. 2017;17(1):18.

7. Thel MC, Califf RM, Tardiff BE, et al. Timing of and risk factors for myocardial ischemic events after percutaneous coronary intervention (IMPACT-II). Integrilin to minimize platelet aggregation and coronary thrombosis. Am J Cardiol. 2000;85(4):427-34

8. Aggarwal NR, Patel HN, Mehta LS, et al. Sex differences in ischemic heart disease: advances, obstacles, and next steps. Circ Cardiovasc Qual Outcomes. 2018;11(2):e004437.

9. Taqueti VR, Shaw LJ, Cook NR, et al. Excess cardiovascular risk in women relative to men referred for coronary angiography is associated with severely impaired coronary flow reserve, Not Obstructive Disease. Circulation. 2017;135(6):566-77

10. Pinkas J, Bojar I, Owoc A, Wierzbińska-Stępniak A, Raczkiewicz D. Cardiovascular diseases, metabolic syndrome and health behaviours of postmenopausal women working in agriculture. Arch Med Sci. 2017;13(5): 1040-8. 
11. Chen WW, Gao RL, Liu LS, et al. China cardiovascular diseases report 2015: a summary. J Geriatr Cardiol. 2017;14(1):1-10.

12. Moran A, Gu D, Zhao D, et al. Future cardiovascular disease in China: markov model and risk factor scenario projections from the coronary heart disease policy model-China. Circ Cardiovasc Qual Outcomes. 2010;3(3):243-52.

13. Lu J, Lu Y, Yang H, et al. Characteristics of High Cardiovascular Risk in 1.7 Million Chinese Adults. Ann Intern Med. 2019;170(5):298-308.

14. Ren Y, Yang H, Browning C, Thomas S, Liu M. Prevalence of depression in coronary heart disease in China: a systematic review and meta-analysis. Chin Med J. 2014;127(16):2991-8.

15. Gao Y, Masoudi FA, Hu S, et al. Trends in early aspirin use among patients with acute myocardial infarction in China, 2001-2011: the China PEACEretrospective AMl study. J Am Heart Assoc. 2014;3(5):e001250.

16. van der Meer MG, Nathoe HM, van der Graaf $Y$, Doevendans PA, Appelman Y. Worse outcome in women with STEMI: a systematic review of prognostic studies. Eur J Clin Investig. 2015;45(2):226-35.

17. Otten AM, Maas AH, Ottervanger JP, et al. Is the difference in outcome between men and women treated by primary percutaneous coronary intervention age dependent? Gender difference in STEMI stratified on age. Eur Heart J Acute Cardiovasc Care. 2013;2(4):334-41.

18. Pendyala LK, Torguson R, Loh JP, et al. Comparison of adverse outcomes after contemporary percutaneous coronary intervention in women versus men with acute coronary syndrome. Am J Cardiol. 2013;111(8):1092-8.

19. Buchanan GL, Chieffo A, Meliga E, et al. Comparison of percutaneous coronary intervention (with drug-eluting stents) versus coronary artery bypass grafting in women with severe narrowing of the left main coronary artery (from the women-drug-eluting stent for LefT main coronary artery disease registry). Am J Cardiol. 2014;113(8):1348-55.

20. Mrdovic I, Savic L, Asanin M, et al. Sex-related analysis of short- and longterm clinical outcomes and bleeding among patients treated with primary percutaneous coronary intervention: an evaluation of the RISK-PCI data. Can J Cardiol. 2013;29(9):1097-103.

21. Mehilli J, Ndrepepa G, Kastrati A, et al. Sex and effect of abciximab in patients with acute coronary syndromes treated with percutaneous coronary interventions: results from Intracoronary Stenting and Antithrombotic Regimen: Rapid Early Action for Coronary Treatment 2 trial. Am Heart J. 2007;154(1):158.e1-7.

22. Glaser R, Herrmann HC, Murphy SA, et al. Benefit of an early invasive management strategy in women with acute coronary syndromes. JAMA. 2002;288(24):3124-9.

23. Morales-Asencio JM, Mancera-Romero J, Bernal-Lopez R, et al. Educational inequalities and cardiovascular risk factors. A cross-sectional populationbased study in southern Spain. Public Health Nurs. 2013;30(3):202-12.

24. Ombrellaro KJ, Perumal N, Zeiher J, et al. Socioeconomic correlates and determinants of cardiorespiratory fitness in the general adult population: a systematic review and meta-analysis. Sports Med Open. 2018;4(1):25.

25. Singh GK, Daus GP, Allender M, et al. Social determinants of health in the United States: addressing major health inequality trends for the nation, 1935-2016. Int J MCH AIDS. 2017;6(2):139-64.

26. Li X, Murugiah K, Li J, et al. 10 year trends in urban-rural disparities in treatments and outcomes after ST-elevation myocardial infarction in China: insights from the China PEACE-retrospective acute myocardial infarction study. Lancet. 2015;S0140-6736(15):00580-2.

\section{Publisher's Note}

Springer Nature remains neutral with regard to jurisdictional claims in published maps and institutional affiliations.

Ready to submit your research? Choose BMC and benefit from:
- fast, convenient online submission
- thorough peer review by experienced researchers in your field
- rapid publication on acceptance
- support for research data, including large and complex data types
- gold Open Access which fosters wider collaboration and increased citations
- maximum visibility for your research: over 100M website views per year
At BMC, research is always in progress.
Learn more biomedcentral.com/submissions

